Bol. Acad. peru. leng. 66. 2019 (163-194)

\title{
LOS RECURSOS DE LA NARRACIÓN PERTURBADORA COMO RASGOS DE REFERENCIALIDAD DE LA FICCIÓN NARRATIVA
}

\author{
THE RESOURCES OF THE DISTURBING NARRATION AS \\ REFERENTIALITY FEATURES OF THE NARRATIVE FICTION
}

\author{
John Harvey Valle Araujo \\ Universidad Nacional Mayor de San Marcos
}

\section{Resumen:}

El presente trabajo parte de considerar el propio proceso creativo del autor como materia de reflexión estética. Con ese propósito, primero deslindamos aspectos conceptuales relacionados con la naturaleza del proceso creativo en el ámbito de la narración. Se reflexiona sobre la naturaleza de la creación estética como tal y sobre la relación de esta con el manejo peculiar de los recursos lingüísticos que hace el autor. Asimismo, se establece el carácter mimético de la ficción debido a que esta se constituye como una representación de lo real por medio del lenguaje. A partir de lo señalado, se demuestra que las estrategias de la narración perturbadora; propuesta por Sabine Schlickers (2017) y sus efectos estéticos en la recepción de los textos corroboran el carácter mimético de la narración, precisamente, porque ese carácter es el resultado de un uso singular del lenguaje. De esa manera, se subraya la imposibilidad de que el arte en general y la narración en particular funcionen al margen del referente del cual necesariamente parten y hacia el cual necesariamente apelan.

https://doi.org/10.46744/bapl.201902.007 


\section{Abstract:}

The present work starts from considering the author's own creative process as a matter of aesthetic reflection. To that end, we first demarcate conceptual aspects related to the nature of the creative process in the field of narration. It reflects on the nature of aesthetic creation as such and on its relationship with the peculiar handling of linguistic resources made by the author. Likewise, the mimetic character of fiction is established because it is constituted as a representation of the real through language. From those indicated, it is demonstrated that the strategies of the disturbing narration proposed by Sabine Schlickers (2017) and their aesthetic effects in the reception of the texts corroborate the mimetic character of the narration, precisely because that character is the result of a use singular language. In that way, it is underscored the impossibility of art, in general, and narration working outside the referent from which they necessarily start and to which they necessarily appeal.

Palabras clave: acto creativo; ficción; narración perturbadora; referencialidad; mímesis.

Key words: creative act; fiction; disturbing narrative; referentiality; mimesis.

Fecha de recepción:

$15 / 09 / 2019$

Fecha de aceptación:

$30 / 11 / 2019$

\section{Introducción}

El acto creativo, en general, constituye un proceso complejo que ha suscitado el interés de múltiples disciplinas con el afán de explicarlo. Más aún cuando se ha tratado de establecer su relación con la realidad o de deslindar cualquier tipo de vínculo con esta. $\mathrm{Al}$ respecto, dos posturas han prosperado: desde una perspectiva posmoderna basada en el psicoanálisis lacaniano, una de estas defiende la idea de que, al ser el lenguaje el único medio que nos acerca a 
lo real, es imposible aprehenderlo en las obras de ficción, porque el lenguaje solo construye universos semióticos a manera de simulacros de lo real que para su aprehensión requieren de un proceso hermenéutico. Este simulacro recibe el nombre de realidad. La segunda postura apuesta, más bien, por la reafirmación del carácter mimético de arte, en tanto que este para ser tal requiere de un contexto que es extratextual o extrasemiótico, más cercano a lo real. Es decir, la obra de arte sí puede representar a la realidad, aunque no de manera literal sino de un modo analógico, metafórico o metonímico por medio de los signos, ya que estos para ser tales han de referir a lo real, del cual forma parte también la instancia receptora que completa el sentido.

A estas dos posturas respecto de la naturaleza del arte se añade el hecho de que en la narrativa, literaria o fílmica, se tenga que recurrir a recursos lingüísticos con un propósito lúdico que va más allá del simple entretenimiento de la audiencia. Para quienes defienden la tesis de la no referencialidad de la obra de arte, esos recursos lúdicos serían evidencia de la autorreferencialidad del arte y del lenguaje en sí mismo. En cambio, para quienes consideramos que el arte no puede desligarse del referente, dichos recursos, más bien, demostrarían el carácter referencial de la obra de arte en general, y de la narrativa ficcional en particular, ya que el efecto lúdico de una novela, de un cuento o de un filme cobrará sentido solo en tanto es transgresión del orden de lo real referido en dichos textos.

En ese sentido, consideramos necesario evaluar si las estrategias de la narración perturbadora, que propone Sabine Schlickers (2017), resaltan la autorreferencialidad del arte o, más bien, reafirman la naturaleza mimética de este. Para ello, partimos de la siguiente pregunta: ¿Los recursos de la narración perturbadora que se introducen en el acto creativo de la ficción narrativa corroboran el carácter referencial de esta? Como respuesta a esta pregunta proponemos como hipótesis que la narración perturbadora es una estrategia lúdica que perturba la recepción de los textos porque infringe la lógica del mundo narrado y propone sus propias reglas de funcionamiento en el texto, razón por la cual exige una relectura de los textos para construir sentido. Dicho sentido a nivel de la recepción solo es posible en relación con el referente o realidad extratextual al que refieren. 
Con el propósito de demostrar nuestra hipótesis, recurrimos primero a la descripción del proceso creativo, para lo cual consideramos los trabajos de Steiner G. (2001/2012) y de Derek Attridge (2011). Posteriormente, procedemos a demostrar la naturaleza referencial del arte a partir de la propuesta de Aristóteles (2013) sobre el concepto de mímesis y del trabajo de Harshaw (1997) relacionado con los campos de referencia. Por último, se analizan y se sintetizan algunas estrategias de la narración perturbadora propuestas por Sabine Schlickers (2017). A partir de lo indicado, se obtienen algunas conclusiones que demuestran la validez de la hipótesis.

\section{La naturaleza del acto creativo}

Referirnos al proceso creativo implica, sin duda, una integración teórica entre estética, filosofía y teología. Tal es la propuesta de George Steiner (2001/2012) quien se cuestiona si en un mundo donde la posibilidad teológica ha sido desplazada y «tirada a la papelera» cabe todavía algún significado para la noción de creación literaria en particular, y de ejecución artística, en general, incluso, para el campo de la filosofía. $\mathrm{Al}$ respecto, la respuesta de este crítico francés bien se puede resumir en la siguiente frase: «[...] en filosofía, no menos que en teología o en poética, el comienzo de la historia es también la historia del comienzo» (29). De esta manera, asocia el concepto de creación — traer al ser y dar forma - con lo divino mediante la construcción discursiva de ese acto. Su postura parte de considerar que los intentos por entender la formulación de las concepciones filosóficas y poéticas actuales no han podido evadir la influencia del discurso religioso-mítico sobre el origen del mundo, lo que concita la atención sobre el campo semántico del vocablo creación.

Propone Steiner (42-47), partiendo de las etimologías hebrea y griega de la palabra, que el acto de creación tendría una doble naturaleza. Así, en la tradición hebrea, la creación sería un acto de habla, una retórica, ya que es el ruab Elobim, el pneuma del creador lo que crea o hace el mundo por medio de su palabra. En este caso, la fórmula retórica de la creación se encuentra en el primer capítulo del Génesis: «Y, dijo 
https://doi.org/10.46744/bapl.201902.007

Dios: sea $[\ldots]$ y fue $[\ldots] »$; también, refiere a lo mismo, aunque desde una perspectiva distinta, el primer capítulo del evangelio de Juan: «En el principio era el Verbo, y el Verbo era con Dios, y el Verbo era Dios. Este era en el principio con Dios» (Biblia, 1960).

De esta manera, para Steiner el acto de crear el mundo es equivalente a decirlo mediante un discurso que es secuencial, razón por la cual, bíblicamente, el acto de creación del mundo le tomó a Dios un lapso de seis días. Pero este no se trataría de un acto solipsista de parte del creador; más bien, en tanto acto de habla o en tanto expresión verbal, su creación exige la presencia de alguien que escuche, de un interlocutor activo que participe en la construcción del sentido de lo creado, precisamente, porque ha sido interpelado por la palabra de creador (a propósito, en el hebreo, elobim es plural, lo que se traduce en la forma «hagamos»). Sin la cooperación de esta instancia receptora, sea el espectador o el lector el acto creativo, la creación artística no sería tal. Por consiguiente, los objetos artísticos serían el resultado de una relación de complicidad entre ambas instancias: el creador y el receptor, interpeladas ambas por el lenguaje.

Entendido de esta manera, el acto creativo para Steiner se condice con la teoría de la recepción, pues según sostiene el crítico: «El espectador, el lector, el oyente se hallan implicados dinámicamente en la realización de la obra de arte. Sus respuestas y sus interpretaciones son esenciales para su significado» (72). La alusión a la socialización de la producción estética convierte a la gestación artística en un acto dialógico tanto con esa «otreidad» ontológica que atestigua el proceso creativo como con la tradición artística al interior del contexto de producción de la obra y con la realidad inmediata del acto creativo. Este hecho implica los componentes sociales, materiales y psicológicos del acto de creación que lo ubican en el devenir histórico (267). Asimismo, esa dialogicidad indispensable del acto creativo acarrea, también, una suerte de desdoblamiento del artista, ya que será el primero en criticar su obra y en realizar un proceso hermenéutico aplicado a su propia producción. Sostiene Steiner (106) que solo el creador, capaz de ser el más agudo crítico y analista de su producción, puede considerarse un verdadero artista. 
Un segundo aspecto para considerar el acto de creación, desde el punto de vista hebreo, es que también implica un acto de violencia en la medida en que el creador y la creación se separan después del acto. Para Steiner, cuando en el Génesis se enfatiza la frase «y vio Dios que era bueno», además de indicar la satisfacción del creador con lo creado, se denota también la despedida, el desapego del hacedor respecto de su obra. Esta, no obstante que contiene las huellas de su hacedor, a partir de ese momento de ruptura, deja su significado a menester del receptor y de sus circunstancias históricas, culturales, filosóficas, estéticas, lingüísticas. Por ello resulta que en muchos casos la semanticidad de la obra supera con creces las propias expectativas de su creador. A tal punto sucede, de esta manera, que bien puede decirse que la obra se va escribiendo o reescribiendo, creando o recreando, no solo según coordenadas espaciotemporales, sino también según aspectos culturales, filosóficos, lingüísticos y estéticos.

Por otra parte, según la tradición griega que también toma en cuenta George Steiner, la creación sería, más bien, un acto erótico. Esta idea se desprende de la interpretación de las exégesis modernas respecto de la raíz griega Xóos (khaos), ya que el vocablo denota un hueco, una ruptura, como el desgarrón de un tejido a través del cual nace la materia (Martinez Nieto, 1997). Al respecto, Olof Gigon (1995) sostiene que «la palabra khaos quiere decir 'hendidura, hondonada' y pertenece al verbo $\chi \alpha \dot{\alpha} \omega$, que en sus formas usuales derivadas puede ser usado, por ejemplo, como abrir desmesuradamente la boca, abrirse una herida, abrirse una caverna en el monte» (30). Por consiguiente, el origen del mundo sería análogo al acto del parto, al nacimiento de la criatura que irrumpe a través de una rasgadura de la matriz que lo ha contenido. Claro que este origen del universo lleva consigo la idea de una fecundación previa, cuestión que implica una presencia antes del ser, por lo que este significado del vocablo creación conlleva una interrogante sobre cuál sería el equivalente de esa matriz; es decir, de «dónde» o de «qué» brota el khaos.

Roxana Martínez (1997: 47), en su estudio filológico de la Teogonía de Hesíodo sostiene que la imposibilidad de determinar con exactitud si khaos es de índole espacial o material, ni cuándo ni de 
https://doi.org/10.46744/bapl.201902.007

dónde nació, sí se podría decir que «el contenido cosmológico de Kahos se encuentra en su propia capacidad de que las cosas ocurran en él, Kahos posee energía interna, no es la pura negatividad, ni el simple opuesto a Gea, entendido como 'disformidad'. Kahos connota, entonces, una fuerza interna que lo caracteriza de manera positiva y le dota de la capacidad propia para que surjan elementos en él. Con ello, la autora deja entrever una semejanza con lo que propone Steiner respecto de Hesíodo. Según el crítico francés, "la existencia se encuentra en el umbral entre el no-ser inconcebible e inexpresable y lo creado”» (45). Sin embargo, si bien es cierto que kahos no puede ser elucidado nunca, da origen a Gea y Eros con lo que la creación deviene más bien en procreación cósmica sobre la base del amor.

En consecuencia, ya sea como acto retórico o como acto erótico, la creación, todo lo que puede ser percibido sensorialmente por el hombre o mediante el auxilio de la ciencia y la tecnología, no sería todo lo que hay. En palabras de Steiner: «La intuición —ihay algo más profundo?-, la conjetura, tan extrañamente resistente a la falsificación, de que existe una "otreidad" fuera de nuestro alcance da a nuestra existencia elemental su tono de insatisfacción. Somos criaturas con una gran sed, obligados a volver al hogar, a un sitio que nunca hemos conocido (...). El deseo de elevación se funda no "porque esté allí, sino, precisamente, "porque esté alli”»(29). De la cita se puede derivar dos conclusiones. En primer término, el acto creativo consiste en una búsqueda de esa «otreidad» siempre esquiva, inasible, o cruelmente castigadora para quien se le acerca más de lo debido. Según la tradición, dice Steiner, profetas y rapsodas son ciegos, precisamente, por su proximidad a la luz. En segunda instancia, se puede afirmar que nada de lo que crea el artista procede de la nada, ya que existe esa «otreidad» que motiva las manifestaciones artísticas como canales para ser. En este caso, para fundamentar esta postura Steiner recurre a Hegel, pues para el filósofo alemán «el comienzo no es una pura nada, sino un no-ser del cual todo llega a ser» (36). Es decir, la creación consistiría en una suerte de extensión de la naturaleza de esa «otreidad» que es la representación del ser absoluto (71) y, en tanto, representación de lo real, es análoga a la obra de arte que para ser recurre al signo, 
al lenguaje, lo que establece ya su constitución mimética. Sobre este último aspecto trataremos más adelante.

Ahora bien, establecidas las cosas de esta manera conviene señalar también que el proceso creativo para Steiner se caracteriza por su carácter contingente, ya que "por imperativos que sean los motivos psíquicos y privados de su génesis, su necesidad no responde a ninguna lógica» (38). De esa manera, la obra de arte deviene en un capricho ontológico, en una suerte de "debería no haber sido», rasgo que en muchos casos ha impulsado no a pocos creadores a la autodestrucción de su obra por considerarlas imperfectas, distantes de aquello que les hubiera gustado hacer, por lo que recurren a escribir muchas versiones de una sola obra, o por considerar que ya han revelado más de lo que tal vez les estaba permitido decir. Sobre este caso, la historia de la literatura cuenta con numerosos casos de autodestrucción. Así sucedía con Malcolm Lowri, que incineraba los manuscritos de sus novelas. Y, si no hubiera sido por la determinación de su esposa, su novela Bajo el volcán, la más importante de las que produjo, se hubiera convertido en ceniza. De igual manera, Ernesto Sábato declaró haber quemado manuscritos previos a El túnel. Incluso el encargo que Kafka le diera a su amigo Max Brod de incinerar todos sus manuscritos es evidencia de esa tendencia «connatural» a todo acto creativo. Para Steiner, ello prueba que solo el arte puede unir el ser en su forma más vívida con la extinción (39). Aunque habría que decir, en este caso, que ese acto de extinción no connota la negatividad del término sino un rasgo positivo, ya que acarrea la idea del resurgimiento, de la resurrección, en busca de «perfección».

A partir de lo dicho, George Steiner define la creación como «aquello que es libertad afirmada y que influye y expresa en su encarnación la presencia de lo que está ausente o de aquello que podría haber sido radicalmente otro» (137). Se desprende de ello que el acto creativo consiste en un ejercicio de libertad absoluta gracias al cual el creador opta por traer al ser la «otreidad», el no-ser, mediante una de las infinitas formas que pudieron haber sido, pero que él mismo las ha decantado siguiendo su libre albedrío. Es, precisamente, esa libertad la 
https://doi.org/10.46744/bapl.201902.007

que va a hacer del artista un ser que se corresponde con la idea de un Dios creador.

Una segunda propuesta sobre la naturaleza del acto creativo en el ámbito específico de la creación verbal que tomaremos como referencia en el presente trabajo corresponde a Derek Attridge. Este crítico sudafricano parte de cuestionarse cómo es que mediante el trabajo de un individuo algo que no ha sido concebido hasta ese momento, de pronto, pasa a ser pensable para toda una cultura, entendida esta como las prácticas, las instituciones y las normas, las creencias y los hábitos de vida, los modelos cognitivos, entre otros elementos que median entre un individuo y el mundo en una determinada época. En su respuesta puede apreciarse cierta coincidencia con la tesis de Steiner, ya que recurre a la experiencia de lo otro al proponer que el acto creativo «[...] se trata de una manipulación del lenguaje por medio de la cual hacemos o permitimos que algo que llamamos "otredad", "alteridad", "lo otro" influya sobre las configuraciones del mundo mental del individuo, esto es, sobre un campo cultural concreto, tal y como se materializa en una subjetividad particular (53)». Dicho de otra manera, como lo explicado por Steiner respecto de la tradición hebrea, la otredad irrumpe en la mismidad mediante un acto retórico. Para Attridge, este acto se trata más bien de un acto-acontecimiento, ya que en tanto acto, la creación se hace deliberadamente a partir del ejercicio de la voluntad del creador; pero al mismo tiempo, en tanto acontecimiento, la creación «le sucede sin avisar a una conciencia pasiva pero alerta» (65). Vista así, la obra de arte modifica la ideocultura, término que se refiere a la encarnación en un individuo de las normas y modos de ser propios de una cultura (53) o, también, a la «la versión individual del entramado cultural a través del cual ha sido constituido como un sujeto con asunciones, predisposiciones y expectativas» (128).

Asimismo, indica Attridge que esa suerte de complicidad entre lengua y alteridad es la responsable de la gestación de los objetos artísticos, y puede producirse esa cooperación, precisamente, porque la obra de arte replica las mismas operaciones lingüísticas y culturales que determinan la mismidad, lo que una vez alude al carácter mimético de la 
obra de arte. Por consiguiente, la creación de una obra de arte consistiría en la realización de una configuración por parte de la ideocultura «de materiales culturales que, al menos para cierto grupo humano y durante un periodo determinado de tiempo, alberga la posibilidad de un encuentro repetido con la alteridad»(68). En este caso, cuando el acontecimiento artístico llega a normalizarse, este deja de tener ese efecto de contacto con la alteridad; es decir, la obra de arte pierde su efecto estético, su particularidad.

Pero en tanto acto-acontecimiento, la obra de arte para Attridge involucra dos instancias, una de carácter activo y otra de carácter pasivoactivo: el creador-creador en el primer caso y el creador-lector en el segundo. Por lo tanto, y aquí una segunda coincidencia con Steiner, ya desde su gestación el acto creativo implica una relación dialógica entre ambas instancias. Así, el significado de la obra de arte supone una red de significados que se va construyendo a partir del diálogo entre el creador y el receptor, que luego va a extenderse hacia toda la cultura en general. Y, como esta es dinámica, procede mediante reelaboraciones de significados de una misma obra de arte. En este proceso, cuanto más cercana a la «otreidad» sea una obra de arte, más reelaboraciones de significado a lo largo del tiempo y del espacio soportará. Este es el rasgo que sustenta la existencia de obras clásicas de los griegos, por ejemplo, que a pesar de los milenios que han transcurrido, todavía siguen conmoviendo a los lectores del siglo XxI, pese a que los sistemas culturales y los sistemas de producción modernos son absolutamente distintos a los de Homero y Sófocles, por ejemplo.

Otra de las propuestas de Attridge que consideramos importante acerca de la creación artística es, precisamente, esa relación de la mismidad con lo otro. Para este autor, «la creación de lo otro» puede entenderse desde una doble significación: como una relación activa que implica la autoría de la mismidad y como una relación pasiva que supone más bien a la alteridad como creadora de la mismidad. En el primer caso, la actividad creativa consistiría en un trabajo de ingenio del autor con, precisamente, esas «posibilidades que ofrecen las formas y los materiales aceptados en su época», de tal manera que el producto artístico deviene 
https://doi.org/10.46744/bapl.201902.007

en «reelaboraciones de modelos ya existentes» (56). En el segundo caso, en cambio, se genera esa sensación de que aquello que el autor quiso decir estuvo siempre ahí, aunque él mismo no puede explicar su origen en términos conscientes y mentales. Por eso, para este teórico de la literatura «[...] parece probable que esta pasividad sea un aspecto importante del modo en que surge lo nuevo [...]. Parece probable que las grandes proezas de creatividad surjan de una apertura de la mente mucho más notable hacia aquello que aún no ha aprehendido» (59). Casos que le sirven de base para su argumento son diversos, y no se reducen solamente al ámbito literario, sino que abarcan otros campos como la filosofía, por ejemplo. Así, Attridge cita a J. M. Coetzee, para quien «resulta inocente pensar que la escritura es simplemente un proceso de dos fases: primero, decides lo que quieres decir y, luego, lo dices. Por el contrario, como todos sabemos, uno escribe porque no sabe qué escribir. La escritura es lo que te revela qué es lo que querías decir [...]. Es en ese sentido que podemos decir que la escritura nos escribe a nosotros mismos. La escritura muestra o crea (y no estamos siempre seguros de si podemos distinguir una cosa de la otra) cuál era nuestro deseo hace un momento» (60). Pero, también, recurre a la confesión de Derridá: «Estoy reflexionando sobre una hipótesis, un argumento lógico, un análisis y, de repente, una palabra surge como la que debo utilizar, gracias a su economía formal [...]. La sensación que tengo no es de haber inventado o de haber sido el autor activo de la cosa en cuestión, sino de haberla recibido por algún golpe de suerte» $(60)$.

Pero, para Attridge, esta afirmación no implica una existencia mística externa al acto creativo encargada de «dictar» la obra, más bien, resalta el hecho de que la relación del acto creativo consciente y la obra creada no obedece a una causalidad directa. Por el contrario, el trabajo creativo implica una suerte de «abandono del control intelectual» en manos de «lo otro» que bien puede permanecer o en la esfera externa o en la dimensión interna del sujeto, y que de todas maneras genera una alteración de la subjetividad. De tal modo, ocurre así que la mismidad resulta transformada por esa alteridad, a tal punto que podríamos afirmar que se produce una reconfiguración de la subjetividad que ha creado lo otro, el cual ya no es completamente otro, sino que ahora pertenece a lo 
familiar. Pero la experiencia de «lo otro» del creador no es transmisible en cuanto tal, sino solamente como testimonio de ese hecho que transmite la reconfiguración ideocultural generada por esa experiencia con la alteridad, para lo cual se hace necesario recurrir al lenguaje, al signo. Por consiguiente, la obra de arte, como testimonio de la alteridad que porta originalidad e inventividad, genera experiencias singulares de lo otro en la instancia de la recepción.

De esta manera, un par de conceptos más —el de originalidad y el de inventividad-, propuestos por Derek Attridge, son relevantes para comprender el acto creativo según su punto de vista. En el primer caso, la originalidad se trata de una cualidad que se revela en el proceso que emprende una ideocultura para traer a la mismidad una otredad que, por ser tal, rebasa las normas y hábitos de una cultura (79). Por lo tanto, la originalidad implica un contacto íntimo con la matriz cultural en la que surge como resultado de una combinación de presiones externas e internas que permiten que un individuo forje una obra de arte donde provoca la manifestación de la otredad en la mismidad (87). De ello se deduce que el concepto de originalidad entraña una diferencia respecto de lo producido anteriormente en el contexto cultural, por lo que este se verá transformada (80). Además, un objeto artístico original servirá de estímulo para la creación, ya sea como reproducción por parte de quienes carecen de originalidad o como soporte de la búsqueda de una nueva originalidad.

¿Pero cómo esa experiencia con «lo otro» marcada por la originalidad consigue transformar el campo cultural, en general, y estimular asimismo la creación como reproducción? Para Attridge, eso es posible cuando la obra de arte creada no solo presenta originalidad, sino además inventividad; es decir, cuando es capaz de generar nuevas entidades artísticas que alteran la cultura porque provocan más experiencias de lo otro. Así, puesto que el objeto artístico está supeditado al contexto cultural e histórico en el que surge, será la instancia de la recepción quien juzgará si la obra de arte es inventiva o no lo es. Por lo tanto, la inventividad no se trata de una cualidad inherente a la obra de arte, más bien, esta se construye retrospectivamente y no es permanente, ya que implica la valoración como tal desde sus receptores culturales. De 
https://doi.org/10.46744/bapl.201902.007

esta condición se deduce que no siempre lo que para los ojos del creador parezca inventivo resulte siéndolo para el receptor (93).

Por último, Attridge propone el concepto de singularidad de la obra de arte. Esta se define como aquello que diferencia una obra de arte de otras de su tipo, «no simplemente como una manifestación particular de unas reglas generales, sino como un entramado concreto dentro de esa cultura que es percibido como resistiendo o excediendo todas las determinaciones generales preexistentes» (122). Es decir, si ese «entramado concreto» que se resiste o excede las posibilidades preprogramadas o asimiladas por los miembros de una cultura requiere de su percepción previa, entonces, se trata también de un acontecimiento, el acontecimiento de singularización que se realiza durante la lectura de la obra, la que — según se dijo- es tal a partir de este acto. Así, pues, la singularidad sucede en la experiencia del lector en tanto este es «depositario de la ideocultura». De ello se colige que la singularidad es dinámica y diversa, pues cada experiencia de la alteridad que genera la obra de arte durante su lectura va a experimentarse como una relación activa de «múltiples voces dirigidas a múltiples destinatarios, de tal manera que incluso el «yo» que lee puede llegar a perder momentáneamente su coherencia» (129). Por consiguiente, la singularidad de la obra de arte jamás está fijada, pues en cada acto de su recepción o lectura esa singularidad se producirá de diferente manera, debido a razones contextuales de cultura, gustos estéticos, factores socioeconómicos, entre otros.

\section{El carácter mimético de la ficción}

En el capítulo IX de la Poética (56), Aristóteles afirma que «la función del poeta no es narrar lo que ha sucedido, sino lo que podría suceder, y lo posible, conforme a lo probable y lo necesario». Esto significa que el creador debe ofrecer proposiciones que sean verdaderas en cualquier contexto, espacio temporal (lo necesario), o por lo menos en uno de estos (lo probable o verosímil). Con ello, el filósofo desliza la idea de que lo posible es tal en cuanto mantiene como su correlato a lo real, lo que desliza el carácter mimético del arte, en general, y de la narrativa en particular. 
Para efectos del presente trabajo se concibe el concepto de mímesis en el sentido aristotélico de imitación o representación del mundo real. Es decir, asumimos que el arte, en general, y la narrativa ficcional, en particular, representan lo real, aunque a partir de una reelaboración de este por medio del lenguaje, mediante procesos analógicos, metafóricos y metonímicos. En ese sentido, la ficción narrativa es solo una evocación de lo real y, como tal, es altamente referencial, puesto que no puede concebirse al margen de lo real. Ciertamente, antes de que los sujetos experimenten lo ficcional han tenido que experimentar lo real, pues solo a partir de las normas que rigen este último lo ficcional puede ser procesado e interpretado por los sujetos. La materia prima de la ficción, incluso de la fantasía proviene del mundo real y a este mismo remite (Espezúa, 2006). Es más, los signos y, con ellos, el lenguaje, en general, adquiere sentido porque refieren a la realidad, la representan. Si así no fuera el caso, taxativamente no habría sentido.

Sobre esta postura referencialista de la ficción se han propuesto ya numerosos trabajos (Garrido, 1997). De estos, en el presente artículo procedemos a sintetizar la propuesta de Benjamin Harshaw (1997), quien recurre a dos conceptos para explicar el tema de la referencialidad. El primero es el Marco de Referencia (MR), definido como un continuo semántico de dos o más referentes —una escena en el espacio tiempo, un personaje, una ideología, la literatura, una crisis económica, el mar, el viento, entre otros - sobre los cuales se puede hablar o intercambiar opiniones. El segundo concepto de Harshaw se refiere al Campo de Referencia (CR), el cual es entendido como un universo que engloba una multitud de MR de diversos tipos, los mismos que se entrecruzan y se interrelacionan los unos con los otros. Los MR pueden ser de diversos tipos: pueden estar presentes o ausentes, según sean o no perceptibles directamente, pueden ser conocidos o desconocidos por los interlocutores, pueden ser reales y concretos o ideales y abstractos, pueden ser iterativos o repetibles o indefinidos e inusuales.

Harshaw, también, establece que si un CR es un universo conformado por MR, se puede presuponer la existencia de un Campo de Referencia Externo (CRE) y de un Campo de Referencia Interno (CRI), 
https://doi.org/10.46744/bapl.201902.007

de tal manera que para interpretar al CRI resulta más que indispensable el CRE. Estos dos campos de referencia pertenecen a dos planos paralelos que nunca se unen, pero que se aluden permanentemente según la lógica de la mímesis referencial. Así, el CRE alude al mundo real que preexiste a lo textual ficcional, a lo extrasemiótico; además, le sirve al texto como sustrato referencial. Por consiguiente, podría tratarse de un periodo histórico, de una ideología, de una cosmovisión como la andina, de un mito, de una experiencia personal, entre otros. En contraste, el CRI se concibe como requisito absoluto y propiedad esencial del texto, y refiere a la realidad proyectada por aquel con la cual se relacionan los significados de ese universo textual. Se caracterizan los CRI porque 1) están configurados de acuerdo con una selección del mundo humano «real», físico, social y físico; 2) un CRI es un objeto semiótico multidimensional antes que un mensaje lineal; 3) se sirven de referentes o de marcos de referencia procedentes de campos externos a ellos, incluyendo el mundo real que abarca creencias, ideologías, religiones, concepciones científicas, situaciones estereotipadas, entre otras; 4) un MRI selecciona elementos y reorganiza sus jerarquías mientras va creando su propio campo autónomo (Harshaw: 136-137).

De lo dicho por Harshaw se desprende que la ficcionalidad es una reorganización de los elementos de un CRE para generar un CRI; es un acto que trae la «otreidad» a la mismidad, en términos de Steiner y Attridge. Ello significa que, por una parte, la construcción del CRI está configurada de acuerdo con los CRE, en la medida en que se necesita del conocimiento del mundo para construir sentido a un texto ficcional; por otra parte, que existe una relación de representación que va desde un CRI hacia un CRE, para lo cual se requiere el concurso del lenguaje.

Finalmente, Harshaw defiende una doble ventaja de acogerse a la teoría de los CRI en lugar de usar términos como «mundo fictivo o posible». Por un lado, crea un vínculo directo entre el mundo proyectado y la referencia lingüística; por otro lado, no se da por supuesta la existencia concreta de objetos, personajes, hechos, ideas o actitudes, sino solo de MR de dichas clases a las cuales el texto remite. Por lo tanto, no tienen sentido relacionar el mundo real o fáctico con el mundo ficcional 
en una obra; más bien, debe relacionarse CRI con CRE, pues el sentido de las palabras está relacionado con referentes específicos propios de los MR, aunque los elementos de los CRE se corresponden con lo real y guardan relación de correspondencia y semejanza con los elementos del CRI, pero no de igualdad. Como vemos, aún desde esta perspectiva, no se hace sino reforzar el carácter mimético de la obra de arte.

Por consiguiente, desde la semántica ficcional, es importante señalar que los textos ficcionales establecen su dominio referencial cuando crean un CRI, el mismo que alude a la realidad proyectada por el texto con la que se relacionan los significados de ese mismo universo textual.

Como se puede constatar, la teoría de los campos de referencia de Harshaw aunque propone alternativas de lo real como referencia de las obras de arte, aun así no pueden evadir la dimensión de lo real como sustrato referencial de sus propuestas. Por consiguiente, las obras de arte devienen en universos semióticos y como tales dependen del lenguaje que es el instrumento de traducción de la «otreidad» a los códigos de la mismidad. $Y$ va a ser precisamente en tanto universos semióticos que las obras literarias van a prestarse al juego de los significantes que lo conforman para producir distintos efectos en su recepción, como son las experiencias perturbadoras.

\section{Recursos de la narración perturbadora en los textos narrativos}

Una de las características de la narrativa moderna es la transgresión sistemática de las reglas de los sistemas narrativos vigentes. Tanto ha sido así que los conceptos narratológicos para describir, categorizar y analizar los nuevos textos se han visto rebasados con creces, situación que ha producido una crisis teórica para abordarlos. En ese contexto, los conceptos previos resultan hasta contraproducentes, como ha sucedido con la categoría de lo fantástico, por ejemplo, más relacionado a aspectos temáticos circunscritos a una época específica relacionada con una línea del romanticismo del siglo xix (Nieto, 2015), pero que no ayuda a dilucidar elementos que más bien se producen en el plano del discurso y que corresponden, básicamente, a muchos textos de los siglos Xx y xxi. 
https://doi.org/10.46744/bapl.201902.007

Es, precisamente, en la búsqueda de nuevas categorías que ayuden a dar cuenta de estas propuestas estéticas modernas que Sabine Schlickers (2017) ha acuñado el concepto de «narración perturbadora». Partiendo de la teoría de la comunicación que concibe como perturbación a los ruidos que interrumpen la comunicación entre el emisor y el receptor, la autora propone que en los textos narrativos la perturbación se trata de una «irritación profunda e intencionada que infringe la coherencia y consistencia del mundo ficcional, y que interrumpe la inmersión o ilusión estética, dirigiendo la atención a la construcción y artificialidad de la narración» (24). Con ello, deja en claro que el efecto perturbador no se debe a aspectos temáticos de los textos, sino básicamente a aspectos formales de los mismos.

Establece Schlickers además que, en cuanto procedimiento narrativo, la perturbación infringe la lógica del mundo narrado y de su representación imprevisible para el lector implícito por lo que obliga una relectura de los textos con el propósito de construir sentido. En cambio, como categoría narratológica, la perturbación es inherente al «sistema» narrativo vigente del texto en cuestión, pues este, por definición, se adhiere mayormente a la doxa, pero se desvía de ella y de sus procedimientos narrativos convencionales en el momento de la perturbación que transgrede o anula las normas implícitas y propone sus propias reglas de funcionamiento para el texto en el que aparece (24).

La narración perturbadora comprende estrategias complejas y lúdicas a las que recurre el autor implícito para producir «intencionalmente efectos desconcertantes como la sorpresa, la confusión, la duda o el desengaño. Estos elementos interrumpen la inmersión en el acto de la percepción, pero generan al mismo tiempo nuevas experiencias de inmersión» (11) para el lector implícito, instancia ficticia que, junto a la de autor implícito, es inmanente a la narración (Chatman, 1990). Esto no quiere decir, sin embargo, que la narración perturbadora suponga una desviación de lo convencionalmente establecido; más bien, aquella se trata de un «juego intencionado, lúcido y creativo con estrategias y recursos narrativos establecidos» (15) para producir un placer de tipo 
estético en el lector implícito de un texto. De ello se desprende que la perturbación que se deriva de estos textos se trata de un «fenómeno intratextual» elaborado por el autor implícito en el proceso creativo de su obra que está dirigida al lector implícito (14), quien por su parte deberá contribuir en la construcción del sentido del texto.

Se colige de lo dicho que la narración perturbadora «juega con la doxa» causando una disrupción en esta, por lo que la intensidad de la experiencia perturbadora depende de factores relacionados con el contexto, la disposición, el conocimiento y las expectativas del receptor, pero también del manejo de los recursos narratológicos en el texto por parte del creador. Por consiguiente, la experiencia perturbadora también será variable en el tiempo y estará subordinada a la convencionalización. De allí que algunos elementos que hayan sido altamente perturbadores en un determinado momento o contexto, en otro ya no lo sean, debido a que estos han sido normalizados, situación que tenderá a disminuir el efecto perturbador del texto. De igual manera, si los receptores del texto no entienden los mecanismos de la doxa y, por lo tanto, no se "prestan para el juego», el efecto perturbador se verá anulado. Por lo tanto, la intensidad de la perturbación narrativa es variable tanto cualitativa como cuantitativamente (24).

Para Schilickers (18), los recursos que provocan la experiencia perturbadora se combinan mediante tres estrategias narrativas: la engañosa, que «conduce a una súbita resemantización de lo leído o visto», precisamente, a causa del engaño de las pistas falsas; la paradójica, que genera contradicciones irresolubles para el lector o espectador, quien no podrá encontrar una solución verosímil o coherente y, finalmente, la estrategia enigmatizante, la cual consiste en proponer enigmas o rompecabezas que no siempre cuentan con una solución y más bien inducen a preguntas sobre lo que es real o imaginario dentro de la ficción. Cada una de estas estrategias cuentan, a su vez, con diferentes recursos para producir el efecto perturbador.

La autora sostiene que para producir una narración perturbadora se deben combinar necesariamente los recursos de varias de estas 
estrategias lúdicas (20). Si no fuera este el caso, el elemento perturbador se perdería y solo se tendrían textos caracterizados de manera aislada por ser engañosos, paradójicos o enigmatizantes. Eso significa que el principio combinatorio de estas estrategias permite clasificar recursos que se excluyen mutuamente o recursos que no pertenecen a una sola estrategia. Para la autora, las posibles combinaciones serían las siguientes: recursos engañosos con recursos paradójicos, recursos engañosos con recursos enigmatizantes, recursos enigmatizantes con recursos paradójicos, o recursos engañosos con recursos paradójicos y con recursos enigmatizantes en un mismo texto (21). Solo al combinarse estas estrategias causan ambigüedad, indeterminación o incoherencia en el texto, y efectos «irritantes» o «extraños» en el lector o espectador, aunque de una manera placentera ajena al temor o hesitación que Todorov estableció como propio de los textos fantásticos del siglo XIX.

Ahora bien, ese rasgo placentero implica que la narración perturbadora solo es posible «en textos con mundos ficcionales verosímiles, en los cuales se transgrede, anula o infringe la doxa para sorpresa del lector implícito» (26), por lo que este se verá en la necesidad de la relectura, con el afán de develar las reglas del juego del que ha sido una víctima feliz. Además, conviene subrayar que el efecto perturbador puede suscitarse desde la instancia de la enunciación o desde la instancia del enunciado. Veamos, a continuación, con mayor detalle cada una de las estrategias.

\subsection{La estrategia engañosa}

Entre estos recursos no fiables en la narración, Sabine Chlickers identifica pistas falsas, técnicas del disimulo, falsas focalizaciones, mentiras, paralepsis, paralipsis, entre otros, que como denominador común causan en el lector el reconocimiento de que ha sido engañado. Por consiguiente, para penetrar el sentido del texto, el lector debe releer el texto y modificar sus hipótesis respecto del funcionamiento del mundo ficcional (33). De lo dicho se desprende que la narración engañosa obedece a un acto deliberado del autor implícito, instancia que restringe esta estrategia a la dimensión intratextual solamente tanto en el plano de la enunciación 
como en el del enunciado, de tal manera que pueda corroborarse la falta de fiabilidad del texto en el mismo acto de la lectura.

Para Schlickers, la «falta de fiabilidad es una técnica narrativa que juega con la transmisión de la información narrativa y la dosificación de la misma y concierne con ello [...] a la focalización. Si el narrador [...] revelara su omnisciencia o la falta de fiabilidad desde el principio, los textos serían muy aburridos. Por eso, a través de su instancia narrativa, el autor implícito restringe consciente e intencionalmente el acceso al conocimiento, introduce pistas falsas, guiños de ojos y provoca hipótesis que se revelan como erróneas» (45). Esta dosificación de la información de parte del autor implícito llegará a su punto de inflexión, generalmente, al finalizar el texto, cuando se produzca la característica más resaltante de esta narración no fiable: la anagnórisis, categoría propuesta por Aristóteles (2013: 60) para señalar una mudanza o cambio de la ignorancia al conocimiento o al reconocimiento por lo que puede entenderse como «descubrimiento».

Esa revelación producirá un giro sorprendente que exige una relectura para identificar mayores pistas que ayuden en la decodificación del texto. De esta manera, los elementos de la narración se resemantizan, debido a que en la relectura adquieren nuevas funciones y significados que justifiquen el giro del texto. En efecto, en cuanto a la relación con la información, hasta antes del giro, el autor implícito sabe más que el lector implícito (focalización cero); después de la anagnórisis, en cambio, ambas instancias disponen de la misma información narrativa, por lo que la focalización cero pasa a ser una focalización interna. Para ilustrar su propuesta, Schilckers recurre a los giros de la enunciación que se producen en los cuentos «Hombre de la esquina rosada» $\mathrm{y}$ «La forma de la espada», de Jorge Luis Borges. En el primer texto, el narrador autodiegético se refiere a sí mismo en tercera persona hasta el final del relato cuando por fin revela al narratario que había estado hablando de sí mismo. En «La forma de la espada», el narrador hipodiegético, «El inglés» que luego resulta ser irlandés, también es no fiable; el narrador homodiegético del inicio es anónimo y narra sobre su encuentro con un hombre misterioso a quien apodan «El inglés». Este, que resulta ser un irlandés, le cuenta 
al narrador homodiegético la historia de su «cicatriz rencorosa» (491). Al final del relato, el mismo narrador hipodiegético revela su identidad: «¿No ve que llevo escrita en la cara la marca de mi infamia? Le he narrado la historia de este modo para que usted la oyera hasta el fin. Yo he denunciado al hombre que me amparó: Yo soy Vincent Moon. Ahora, desprécieme» (495). Pero no solo se produce esa anagnórisis en el nivel hipodiegético; líneas antes, el narrador homodiegético que ha controlado el relato, también, identifica a su narratario: «Borges: A usted que es un desconocido, le he hecho esta confesión. No me duele tanto su menosprecio» (495). De esta manera, ambos cuentos culminan con una metalepsis vertical del enunciado, ya que el narratario resulta siendo el autor ficcionalizado.

Respecto de la narración no fiable en el plano del enunciado, sostiene Sabine Schlickers que la anagnórisis final, el giro sorprendente, revela su no fiabilidad a nivel del enunciado. Para ilustrar con mayor detalle este caso, la autora recurre al cuento «El móvil» de Julio Cortázar. En un primer momento, el tema de este texto es la «venganza» de la muerte de un amigo del narrador autodiegético; sin embargo, al final del cuento, el asunto deriva en la traición, ya que, en lugar de vengar la muerte de su amigo, más bien termina haciendo causa común con su asesino. «Secreto por secreto, los dos cumplimos. De él nunca supe más nada, después que me acomodó entre sus amigos franchutes. A los tres años ya pude volverme. Tenía unas ganas de ver Buenos Aires» (359).

En síntesis, sobre la narración no fiable, la autora establece: a) el rasgo más importante de esta narración es el giro sorprendente que revela el engaño del lector implícito; b) se trata de un engaño deliberado del autor implícito al lector implícito mediante un narrador; c) la narración fiable solo puede tener lugar en textos ficcionales debido al desdoblamiento de la situación comunicativa entre el autor y el lector implícitos; d) esta estrategia narrativa puede aplicarse tanto en el enunciado como en la enunciación, y e) es una narrativa intertextual intencional por lo que se descartan errores o indicios extratextuales que aludan a la no fiabilidad del texto. 


\subsection{La estrategia paradójica}

Respecto de esta segunda estrategia perturbadora, Sabine Schlickers admite que en la narrativa una paradoja es un recurso de puesta en entredicho poetológico, "por el cual las normas y reglas que constituyen la obra literaria sincrónica y diacrónicamente entran en contradicción consigo mismas» (90), por lo que también se ve comprometida la doxa, puesto que se produce efectos desconcertantes en la recepción de los textos. En ese sentido, los recursos paradójicos que consideramos en este trabajo son la metalepsis, la mise en abyme y el bucle infinito.

\subsubsection{La metalepsis}

Según Genette, el teórico que introdujo esta categoría narratológica a partir de la retórica, la metalepsis se define como «toda intrusión del narrador o del narratario extradiegético en el universo diegético (o de personajes diegéticos en el universo metadiegético, etc.), o inversamente» ([1972] 1989: 290), y que, además, produce un efecto extraño que puede ser cómico o fantástico (2004: 244), debido a que la metalepsis es una «[... ficción de tipo fantástico o maravilloso, que no puede conseguir una completa suspensión de la incredulidad, sino solo una simulación lúdica de la credulidad» (28). Además, en este último trabajo, el teórico francés complementa su primera propuesta señalando que la metalepsis refiere a «una manipulación — al menos figural, pero en ocasiones ficcional [...] - de esa peculiar relación causal que une [...] al autor con su obra o, de modo más general, al productor de una representación con la propia representación [...]» (15). Pero conviene señalar que este recurso perturbador jamás suspende la ilusión estética del receptor, sino, más bien, la enriquece, puesto que puede constituir una nueva ilusión estética apelando a los bordes entre la realidad y la ficción. Por supuesto, siempre dentro de la ficción, ya que el narrador y el narratario son entes ficticios, mientras que el autor y el lector son reales (Schlickers: 92).

La metalepsis puede producirse a nivel de la enunciación y del enunciado. Ambas estrategias podrían manifestarse en forma vertical al pasar de un nivel narrativo a otro, de manera descendente 
https://doi.org/10.46744/bapl.201902.007

o ascendente, o en forma horizontal, en el mismo nivel narrativo (96). Así, en la metalepsis vertical de la enunciación se requiere de «dos situaciones comunicativas subordinadas que se transgredan una o varias veces a lo largo de la narración» (105). En este tipo de metalepsis, alguna de las instancias transgrede el nivel narrativo al que pertenece. Un caso ilustrativo de esta metalepsis, de manera ascendente, se produce cuando un personaje, que se encuentra en el nivel intradiegético, se dirige al narrador o al narratario que se encuentran en el nivel extradiegético, o al autor implícito que se encuentra en el nivel intratextual.

En cuanto a la metalepsis vertical del enunciado, esta se produce cuando dos órdenes ontológicas o espaciales o temporales se transgreden hacia abajo o hacia arriba. Schlickers ilustra este tipo de metalepsis con el cuento "Las historias que me cuento", de Julio Cortázar (1998). En la hipodiégesis, el narrador ha imaginado ser un camionero que una noche encuentra a una mujer a orillas de la carretera y tiene una aventura sexual con ella. En su imaginación, el nivel hipodiegético, el narrador protagonista se sorprende de que la mujer sea Dilia, una amiga casada que suele frecuentar en su realidad ficcional, nivel intradiegético. Cuando meses después se encuentra con ella, esta le cuenta que tuvo un accidente en una carretera y que, de pronto, apareció un camionero que la auxilió llevándola consigo. El hecho le ha dejado a Dilia traumatizada, pues «es algo que vuelve y vuelve» (407). Entonces, interviene el comentario del narrador en el mismo plano: «Ella quizás no, Dilia quizá no sabía por qué, pero yo sí» (407). Y, añade más adelante: «Ella no podía comprender de este lado de la historia» (408). Con esto, el narrador intradiegético expresa su posición de ventaja respecto de lo que Dilia desconoce en relación con ese plano hipodiegético, el mundo imaginario del narrador. En conclusión, este cuento de Cortázar es ilustrativo de la metalepsis vertical del enunciado en sentido ascendente entre los niveles hipodiegético e intradiegético.

Sobre la metalepsis horizontal de la enunciación, Schlickers sostiene que se requiere de «dos o más situaciones comunicativas 
paralelas, autónomas y separadas espacialmente en el mismo nivel narrativo, que se entrecrucen de forma paradójica» (126). Un cuento que ilustra el caso sería «Segunda vez», de Julio Cortazar (1998: 134139). En este texto, desde la mitad del segundo párrafo, la voz narrativa cambia repentinamente de un narrador homodiegético a otro heteroextradiegético. Para que se produzca la metalepsis horizontal del enunciado, en cambio, Sabine Schlickers (130) señala que es necesaria la existencia paralela de «dos órdenes espaciales, temporales y/u ontológicos distintos, separados y considerados infranqueables que se transgredan paradójicamente, produciendo un efecto fantástico». Esto sucede, por lo general, en los textos de ciencia ficción donde se producen invasiones desde otros planetas, fantasías distópicas, o en los casos de desdoblamientos de sujetos, como ocurre en el cuento «Distante espejo» también, de Cortázar (1998: 83-87).

\subsubsection{El bucle infinito}

Para Schlickers, este recurso consiste en un encadenamiento de los hechos, pero sin variación. La figura emblemática de esta estrategia es la serpiente que se muerde la cola, conocida como ouroborus. Ilustran este recurso aquellos textos o filmes que terminan con la frase o escena que da inicio a la obra, de tal manera que el lector ideal puede volver a empezar su lectura. Tal sucede en la segunda línea de lectura que propone el autor en Rayuela (Cortazar, 2011): del capítulo 58 remite al 131 y de este, a su vez, nuevamente al 131.

\subsubsection{La mise en abyme}

Se trata del reflejo de la historia o de parte de esta mediante una reduplicación simple, repetida o engañosa, sin que esto último signifique una duplicación o repetición literal del texto o sus partes. Sobre esta característica, Meyer-Minnemann (2006) aclara que la mise en abyme se trata, básicamente, de un desdoblamiento por analogía y no por identidad. De manera similar a lo que ocurre con la metalepsis, sostiene Schlickers que también la mise en abyme podría generarse en el plano de la enunciación y en el enunciado y, en ambos casos, 
https://doi.org/10.46744/bapl.201902.007

ocurre según los distintos niveles narrativos de manera horizontal o de manera vertical. En este caso, el principio predominante de la mise en abyme vertical es el encajamiento, como cajas chinas, opuesto al encadenamiento de la mise en abyme horizontal (226) que, para Schilckers, se ilustra tanto en las novelas episódicas como en la picaresca, o el Quijote.

\subsection{La estrategia enigmatizante}

La tercera estrategia perturbadora que propone Sabine Schlickers (168 y ss.) consiste en la presencia de acertijos en los textos para que el lector los resuelva o siquiera intente resolverlos. Como, en cierto sentido, todos los textos narrativos proponen, en cierto modo, acertijos respecto de lo que sucederá en seguida y del significado del mundo representado, la autora propone dos criterios para distinguir la enigmatización perturbadora de la que no lo es. El primero de estos «concierne a la función semántica de la enigmatización, estrategia desorientadora que se usa del modo que el mundo narrado y la acción no resulten reconstruibles de inmediato o con certeza» (269). De esa manera, pretende la desorientación del lector, a quien se desafía para que mediante procesos cognitivos complete los elementos que en apariencia son incompatibles, incoherentes, o carecen de información relevante para la comprensión del enunciado o de la enunciación (269). El segundo criterio que permite identificar la enigmatización perturbadora se relaciona, en cambio, con las estructuras narrativas específicas. En este caso, debe distinguirse entre la indeterminación, cuando se presenta de manera incompleta o poco concreta información que es relevante, y la ambigüedad, cuando coexisten dos contrarios o contradicciones que se excluyen mutuamente.

La narración enigmatizante por indeterminación «se beneficia de una representación incompleta, poco concreta, ambivalente, fragmentada $o$ indirecta de algo que el receptor tiene que completar y determinar cognitivamente para poder otorgarle un sentido y una forma coherente» (373). Por consiguiente, no se puede reconstruir el mundo narrado de manera unívoca, debido a que su rasgo fundamental es la omisión de información relevante de los mundos narrados, ante lo cual el lector 
tiende de manera natural a completar los hiatos informativos, experiencia que le provoca goce al mismo tiempo. Claro que ese goce dependerá de los modelos culturales o subjetivos de la instancia receptora del texto. A partir de estas características, Schlickers propone la existencia de rompecabezas narrativos en el caso de que la enigmatización se resuelva al interior de la diégesis, y los enigmas narrativos, si es que el final es abierto. Ello significa que la solución o el dato a descubrir no debe ser explícito y, más bien, debe presentarse de manera ambivalente o mediante pistas falsas (270).

En cuanto a la ambigüedad, ya se dijo que se produce por efecto de una contrariedad o de una contradicción simultánea de elementos coexistentes que se excluyen mutuamente (Schlickers: 281). Además, sostienen la autora que la ambigüedad se produce en tres dimensiones: en el estatus ontológico de lo narrado, en el estatus pragmático del discurso, y en el orden espaciotemporal y causal de lo narrado (282). El ejemplo literario al que recurre Schlickers para ilustrar la ambigüedad narrativa es el cuento «El sur», de Borges. En este texto, la autora establece dos planos donde el segundo es reflejo del primero. Al respecto, el mismo Borges ha indicado las correspondencias entre ambas partes: el tomo de Las mil y una noches, que figura en ambas partes; el coche de plaza, que primero lo lleva al sanatorio y luego a la estación; el parecido entre el patrón del almacén y un empleado del sanatorio; el roce que siente Dahlmann al hacerse la herida en la frente, y el roce de la bolita de miga que le tira el compadrito para provocarlo. De esta manera, el final del cuento puede significar efectivamente la muerte inevitable de Dahlmann en la llanura o, más bien, una alucinación provocada por las fiebres de la septicemia.

\subsubsection{La narrativa fantástica}

Sabine Schlickers (296 y ss.) propone que lo fantástico es una forma de indeterminación, por lo que no se trata de un género, como había considerado Todorov, para quien los fantástico deriva de la intromisión de una realidad externa en la diégesis del texto con lo que se producía una hesitación en el lector. Para la autora, lo fantástico se trata más bien de un modo narrativo, de una estructura textual dependiente del 
https://doi.org/10.46744/bapl.201902.007

contexto histórico y cultural. Así, en cuanto estructura narrativa, lo fantástico propone una duda ontológica a partir de una contradicción entre el mundo narrado, el cual está modelado según las normas de la realidad extratextual, y un evento imposible que irrumpe en el mismo y que, además, no es compatible con esas normas ontológicas y físicas. Claro está que la irrupción de ese elemento imposible, en relación con la idea de lo real del lector ideal, sucede solo a nivel de la representación discursiva, debido a que física y lógicamente es imaginable, aunque no pueda ser explicado. De ello se puede concluir señalando que lo fantástico no radica en la hesitación del receptor, como Todorov propuso, sino en la inexplicabilidad del suceso según las normas del mundo extratextual.

Se concluye de lo dicho que lo fantástico corresponde a la estrategia enigmatizante, puesto que propone enigmas irresolubles en un mundo que ha sido modelado según el orden de lo verosímil o, dicho de otra manera, la irrupción de lo imposible en lo familiar, en el universo ficticio verosímil, provoca efectos inquietantes e incomprensibles y por eso mismo amenazadores, pero que no causan hesitación, sino una perturbación placentera. Es por ello que antes de la manifestación o aparición del «elemento imposible [...] no se percibe ningún sistema u orden alternativo complejo, y el supuesto segundo sistema de realidad (maravilloso) no adquiere ningún perfil reconocible ni se dan a conocer sus reglas (las cuales son imprescindibles para poder hablar de un sistema). Es más, un texto fantástico destaca, justamente, por no evocar un mundo maravilloso reconocible como realidad paralela, por lo cual lo fantástico nace del único orden existente» (Schlickers: 303).

Por consiguiente, lo fantástico deviene en solo representación discursiva de lo imposible imaginable y, por eso, representable. Uno de los textos que le sirven a la autora para ilustrar su propuesta es «Autopista del sur», de Julio Cortázar. En este cuento, la prolongación del atasco en una autopista del sur de París, incluso, por meses, sin que se les informe a las personas las razones que lo provocaron, sin que ellos mismos se interesen por escapar de semejante situación, acentúa lo insólito. A ello se añade que el narrador extraheterodiegético contribuye a la narración objetiva de los hechos (307). 


\section{Conclusiones}

El acto creativo puede concebirse, desde la tradición hebrea, como un acto de habla, en tanto se constituye como tal a partir de la interacción de dos instancias: el autor y el lector implícitos, pero al mismo tiempo puede verse como un acto erótico, un parto; ya que consiste en traer la alteridad a la mismidad mediante una rasgadura connotada en la raíz griega de Xóoৎ (khaos). Asimismo, los objetos artísticos que surgen de este acto creativo, todos ellos son representaciones de lo real por medio del lenguaje, por lo que el arte, en general, presenta un carácter mimético que apela al referente. Dicho esto, la narración perturbadora solo se produce a nivel de la representación. No puede producirse extra textualmente porque las normas de lo real no se pueden alterar. Esta condición restrictiva resalta que el efecto perturbador solo será posible en relación con el referente del texto.

Con ello, la teoría clásica de lo fantástico ya no tiene sentido en los textos modernos a los que equivocadamente se les ha catalogado como fantásticos; además, el efecto se trata, más bien, de una perturbación placentera por ser el resultado de una propuesta lúdica del lenguaje, y ya no más de una hesitación, como proponía Todorov. Por lo tanto, es imposible que el arte, en general, y la narración, en particular, funcionen al margen del referente del cual necesariamente parten y hacia el cual necesariamente apelan. 


\section{BIBLIOGRAFÍA}

ARISTÓTELES. (2013). Poética. Madrid: Alianza Editorial.

ATTRIDGE, D. (2011). La singularidad de la Literatura. Madrid: Abada Editores.

BORGES, J. L. (1974). Obras completas. Buenos Aires: Emecé Editores.

. (1952). Magias parciales del Quijote. En Otras inquisiciones. Buenos Aires: Sur, 55-58.

CORTÁZAR, J. (1998). Cuentos completos. Vol. I y II. Madrid: Alfaguara.

DOLEŽEL, L. (1980). Truth and authenticity in narrative. En Poetics Today. Vol. 1, $\mathrm{N}^{\circ}$ 3, 7-25. Duke University press.

. (1999). Heterocósmica. Ficción y mundos posibles. Madrid: Arco Libros.

ENAUDEAU, C. (1999). La paradoja de la representación. Buenos Aires: Paidós.

ESPEZÚA, D. (2006). «Ficcionalidad, mundos posibles y campos de referencia». Dialogía, revista de lingüística, literatura y cultura, 1, 69-96.

ESTÉBANEZ, D. (2004). Diccionario de términos literarios. Madrid: Alianza Editorial.

FILINICH, M. (2011). Enunciación. Buenos Aires: Eudeba.

GARRIDO, A. (1997). (Comp.). Teorías de la ficción literaria. Madrid: Arco/Libros.

GENETTE, G. (2004). Metalepsis: de la figura a la ficción. Buenos Aires: FCE. 
https://doi.org/10.46744/bapl.201902.007

. (1983/1998). Nuevo discurso del relato. Madrid: Cátedra. . (1972/1989). Figuras III. Barcelona: Lumen.

GIGON, O. (1995) Los orígenes de la filosofía griega: de Hesíodo a Parménides. Madrid: Gredos.

HARSHAW, B. (1997). Ficcionalidad y campos de referencia. En Teorías de la ficción literaria. Madrid: Arco/Libros, 123-157.

JORDAN, M. (1998). La narrativa fantástica. Evolución del género y su relación con las concepciones del lenguaje. Madrid: Vervuert Iberoamericana.

KIRKHAM, R. (1992). Theories of Truth: A Critical Introduction. Cambridge: MITT Press.

LANG, S. (2006). Prolegómenos para una teoría de la narración paradójica. En: Grabe, Nina; Lang, Sabine; MeyerMinnemann, Klaus (Eds.), La narración paradójica. «Normas narrativas» y el principio de la «transgresión». Madrid: Fráncfort: Iberoamericana/Vervuert, 21-48.

LUTAS, L. (2015). «Paradoja y metalepsis narrativa en el cuento "El otro”, de Jorge Luis Borges». Tópicos del Seminario (34), 131-153.

MARTÍNEZ, F. (2001). La ficción narrativa. Su lógica y Ontología. Santiago de Chile.

MARTÍNEZ, R. (1997). Estudio Sobre las cosmogonías prefilosóficas griegas. Tesis de la Universidad Complutense de Madrid, Facultad de Filología, Departamento de Filología Clásica.

MEYER-MINNEMANN. (2006). Narración paradójica y ficción. En Nina Grabe, Sabine Lang y Klaus Meyer-Minnemann 
https://doi.org/10.46744/bapl.201902.007

(Comp.), La narración paradójica. Madrid/Frankfurt: Iberoamericana/Vervuert, 49-71.

NIETO, O. (2015). Teoría general de lo fantástico. Del fantástico clásico al posmoderno. México D. F.: Universidad Autónoma de la Ciudad de México.

. (2016). «El sistema de lo fantástico: la quintaesencia de la literatura». Revista Ciencias, Vol. 67, N. ${ }^{\circ}$ 4. México D. F.: Academia Mexicana de Ciencias, 18-23.

OATES, J. C. (1996). La naturaleza del cuento. En: Lauro Zavala, (ed.), Poéticas de la brevedad. Teorías del cuento III. México: UNAM, 117-128.

QUESADA GÓMEZ, C. (2008). Incursiones de la metaliteratura en lo fantástico: a propósito de la metalepsis en Hispanoamérica. En Ensayos sobre ciencia ficción y literatura fantástica: actas del Primer Congreso Internacional de literatura fantástica y ciencia ficción. Teresa López Pellisa y Fernando Ángel Moreno Serrano (Eds.). Universidad Carlos III de Madrid, 293-305.

ROAS, D. (2014). El reverso de lo real: Formas y categorías de lo insólito. En Javier Ortiz (Ed.), Estrategias y figuración de lo insólito en la narrativa mexicana (siglos XIX y XX). Oxford: Lang, 9-30.

. (2001). La amenaza de lo fantástico. En Teorías de lo fantástico. Madrid: Arco-Libros, 7-45.

SARLO, B. (1995). Paradojas y otros escándalos. En Borges, un escritor en las orillas. Buenos Aires: Ariel, 130-144.

SCHLICKERS, S. (2017). La narración perturbadora: un nuevo concepto narratológico transmedial. Madrid: Iberoamericana. 
John Harvey Valle Araujo

https://doi.org/10.46744/bapl.201902.007

TODOROV, T. (1970). Introducción a la literatura fantástica. Buenos Aires: Tiempo Contemporáneo.

TRAILL, N. (1996). Possible Worlds of the Fantastic: The Rise of the Paranormal in Literature. Toronto: Universidad de Toronto Press. 